\title{
Studies of biouptake and transformation of mercury by a typical unicellular diatom Phaeodactylum tricornutum
}

\author{
DENG GuiFu ${ }^{1}$, ZHANG TianWen $^{1}$, YANG LiMin $^{1^{*}} \&$ WANG QiuQuan ${ }^{1,2^{*}}$ \\ ${ }^{1}$ Department of Chemistry \& the Key Laboratory of Analytical Science, College of Chemistry and Chemical Engineering, Xiamen University, \\ Xiamen 361005, China; \\ ${ }^{2}$ State Key Laboratory of Marine Environmental Science, Xiamen University, Xiamen 361005, China
}

Received May 16, 2012; accepted July 18, 2012; published online October 24, 2012

\begin{abstract}
Mercury $(\mathrm{Hg})$ is a toxic heavy metal with its biogeochemical cycling in the ocean depending on the type and behavior of the oceanic microalgae. The present work aimed to evaluate bioaccumulation and transformation of $\mathrm{Hg}$ by Phaeodactylum tricornutum, a typical unicellular diatom, when exposed to the extremely high level of $\mathrm{Hg}$ in order to understand the possible mechanisms of acute stress response. P. tricornutum can accumulate $\mathrm{Hg}$ (its bioaccumulation factor is at $10^{4}$ level), and the $96 \mathrm{~h} \mathrm{EC}_{50}$ was estimated to be $145 \mu \mathrm{g} \mathrm{L}^{-1}$. The amounts of surface-bound $\mathrm{Hg}$ being about 1.2 to 4.8 times higher than those of intracellular $\mathrm{Hg}$ under exposure to $\mathrm{HgCl}_{2}$ (from 20 to $120 \mu \mathrm{g} \mathrm{L} \mathrm{L}^{-1}$ concentrations) suggested that the cell wall of $P$. tricornutum is an important "fence" towards $\mathrm{Hg}$. After entering the P. tricornutum cell, $\mathrm{Hg}$ underwent transformation in its chemical form via interactions with high molecular weight sulfur-containing proteins (accounting for $68 \%$ of the intracellular $\mathrm{Hg}$ ), and glutathione as well as the induced phytochelatins (PCs) $(24 \% \mathrm{Hg})$ which alleviated the toxicity of $\mathrm{HgCl}_{2}$. In addition, the existence of organic ligands greatly influenced the uptake and transformation behavior of $P$. tricornutum towards $\mathrm{HgCl}_{2}$, especially in the case of cysteine (Cys), which increased the uptake of $\mathrm{Hg}$, but alleviated the toxicity of $\mathrm{Hg}$ towards $P$. tricornutum due to the fact that Cys is an important precursor for the synthesis of PCs inside the cell. The uptake process of $\mathrm{Hg}$ by P. tricornutum was in agreement with the Freundlich isotherm, suggesting a typical heterogeneous sorption process. More importantly, we observed the conversion of $\mathrm{HgCl}_{2}$ into methylmercury inside the $P$. tricornutum cells and its release into the culture solution using HPLC/CVG-AFS and GC-MS, although the mechanism needs to be further investigated.
\end{abstract}

mercury, methylmercury, P. tricornutum, species transformation, toxicity, phytochelatin

Citation: Deng G F, Zhang T W, Yang L M, et al. Studies of biouptake and transformation of mercury by a typical unicellular diatom Phaeodactylum tricornutum. Chin Sci Bull, 2013, 58: 256-265, doi: 10.1007/s11434-012-5514-3

Microorganisms are able to accumulate heavy metals via both ways of surface-bound sorption and intracellular involvement [1]. The cell walls of microorganisms contain many different functional groups such as amine, carboxyl, hydroxyl, sulfates and phosphates, which interact with heavy metals. Microorganisms can also produce proteins and/or polypeptides such as metallothioneins and other cysteine-rich peptides which complex heavy metals and thus detoxify them in the cells [2]. On the other hand, many kinds of natural and anthropogenic ligands are always pre-

*Corresponding authors (email: lmyang@xmu.edu.cn; qqwang@xmu.edu.cn) sent in the aquatic environment, and heavy metals may form complexes with such existing ligands resulting in various chemical species, determining significantly the modes and amounts of the heavy metals to enter into the cells of microorganisms. In addition, some heavy metals may be transformed to methylated compounds by microorganisms [3]. All these accumulation and transformation processes affect the fate and transport of heavy metals in the environment.

As one of the typical toxic heavy metals, mercury $(\mathrm{Hg})$ pollution is a global problem because of its persistence, bioaccumulation and toxicity in the environment [4,5], and 
therefore is a risk factor for the health of people [6,7]. $\mathrm{Hg}$ can take a myriad of pathways to enter the environment, but one of the main sources of $\mathrm{Hg}$ to most aquatic ecosystems is the atmospheric deposition of $\mathrm{Hg}$ through long-distance atmospheric transport from anthropogenic and natural sources. Generally, the concentration of total $\mathrm{Hg}$ is less than $0.12 \mu \mathrm{g} \mathrm{L}^{-1}$ in seawater [5], however, the $\mathrm{Hg}$ concentration is as high as $2.3 \mu \mathrm{g} \mathrm{L}^{-1}$ or even $260 \mu \mathrm{g} \mathrm{L}^{-1}$ in some seriously polluted areas [8,9]. Many marine organisms take part in and may play an important role in its biogeochemical cycling in the ocean. Phaeodactylum tricornutum is a unicellular diatom distributed widely in oceanic and fresh waters. It is at the bottom of aquatic food chains, and may be consumed by the next higher level. It represents a major entry point of toxic heavy metals to the organisms at higher trophic levels, leading to their accumulation and bioamplification in higher organisms along the food chains [10,11]. Additionally, because of its known structure and genome [12], it has frequently been used as a model diatom in studies of algal physiology and ecology as well as studies of heavy metal transportation and transformation in the oceanic ecosystem [13]. However, previous studies on P. tricornutum were mainly focused on the accumulation, transformation and toxicity of cadmium and copper, those concerning $\mathrm{Hg}$ are scarce [14].

The purpose of our present study was to investigate the bioaccumulation and transformation of $\mathrm{Hg}$ by $P$. tricornutum. The accumulation behavior and toxicity of various $\mathrm{Hg}$ species to $P$. tricornutum as well as the conversion of $\mathrm{Hg}$ species inside the cell were studied when $P$. tricornutum was exposed to the extremely high level of $\mathrm{Hg}$ species in order to understand the possible mechanisms of acute stress response and the role of microalgae during the biogeochemical cycling of $\mathrm{Hg}$ in the marine environment.

\section{Experimental}

\subsection{Reagents and chemicals}

3-N-morpholino-propane-sulfonic acid (MOPS) purchased from Sangon Biological Engineering Technology \& Services Co. Ltd. (SBETS, Shanghai, China) was used to control the acidity of seawater culture solutions at $\mathrm{pH}$ 7.5. Chymotrypsin, $\beta$-lactoglobulin, insulin, vitamin $\mathrm{B}_{12}$ and glutathione from SBETS were used as molecular weight standards to calibrate the molecular weight of $\mathrm{Hg}$ associated with proteins and peptides expressed in P. tricornutum using size-exclusion chromatography. $\mathrm{HgCl}_{2}$, humic acid (HA), tryptophan (Trp), methionine (Met), cysteine (Cys), nitrilotriacetic acid (NTA) and ethylenediamine tetraacetic acid disodium salt (EDTA), which were used as model ligands during $\mathrm{Hg}$ exposure experiments towards P. tricornutum, were obtained from Sinopharm Chemical Reagent Co. Ltd. (SCR, Shanghai China). Sodium borohydride $\left(\mathrm{NaBH}_{4}\right)$, tributyl phosphine (TBP), acetonitrile (ACN), trifluoroace- tic acid (TFA) as well as 5,5-dithiobis(2-nitrobenzoic acid) (DTNB), used for the reduction and derivatization of phytochelatins (PCs) during the extraction, HPLC separation and determination of PCs, were purchased from SigmaAldrich (St. Louis, MO, USA); dichloromethane $\left(\mathrm{CH}_{2} \mathrm{Cl}_{2}\right)$, methanol, mercaptoethanol ( $\beta$-ME), dithioerythreitol (DTE), ammonium acetate $\left(\mathrm{CH}_{3} \mathrm{COONH}_{4}\right)$ and formic acid $(\mathrm{HCOOH})$, used for selective methylmercury $(\mathrm{MeHg})$ extraction and HPLC-AFS determination with photo-induced cold vapor generation (CVG) [15-17], were purchased from Merck (Darmstadt, Germany); sodium tetraphenylborate $\left(\mathrm{NaBPh}_{4}\right)$, also from SCR, was used to derivatize $\mathrm{MeHg}$ for GC-MS analysis; and ultrapure water (18 M $\Omega$ ) was prepared with a Milli-Q system (Millipore, Bedford, MA, USA), and was used throughout this study. Other reagents used in this study were at least of analytical grade.

\subsection{Instrumentation and optimum conditions}

$\mathrm{Hg}$ determination and speciation were performed on a nondispersive atomic fluorescence spectrometer (AFS, Beijing Rayleigh Analytical Instrument Corporation, China) with a UV-HCOOH induced CVG unit coupled with a Shimadzu LC-2010A system (Kyoto, Japan). An Hg lamp (253.7 nm) was used as an excitation source (Beijing Institute of Vacuum Electronics Research, China) [15-17]. A lamp current $(30 \mathrm{~mA})$, voltage $(-310 \mathrm{~V})$, observation height $(7 \mathrm{~mm})$ and Ar flow rate $\left(300 \mathrm{~mL} \mathrm{~min}^{-1}\right)$ were optimized and adopted for AFS determination. An Agilent $\mathrm{C}_{18}$ column (particle size, $5 \mu \mathrm{m} ; 4.6 \mathrm{~mm}$ I.D. $\times 250 \mathrm{~mm}$ in length), and an isocratic elution with $2 \% \mathrm{CH}_{3} \mathrm{OH}-\mathrm{H}_{2} \mathrm{O}$ containing $0.1 \% \beta-\mathrm{ME}$ and $0.06 \mathrm{~mol} \mathrm{~L}^{-1} \mathrm{CH}_{3} \mathrm{COONH}_{4}$ buffer (pH 6.8) at flow rate of

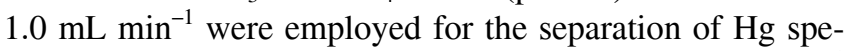
cies, and a low-pressure $\mathrm{Hg} \operatorname{lamp}(40 \mathrm{~W})$ and $1.9 \mathrm{~mol} \mathrm{~L}^{-1}$ $\mathrm{HCOOH}$ were used for $\mathrm{Hg} \mathrm{CVG}$. Fourier transform infrared spectroscopy (FT-IR) (Nicolet Avatar 360, Thermo Fisher Scientific, USA) was used to investigate the interaction between $\mathrm{Hg}$ and cell walls. Reverse-phase HPLC for the separation and determination of the $\mathrm{Hg}$ - and $\mathrm{Cd}$-induced PCs was carried out on an Agilent 1100 series chromatographic system (Agilent Technologies, Palo Alto, CA) equipped with a UV-Vis detector $(190-600 \mathrm{~nm})$. A $C_{18}$ reverse phase column (particle size, $5 \mu \mathrm{m}$; $2.0 \mathrm{~mm}$ I.D. $\times 250 \mathrm{~mm}$ in length; Shimadzu, Japan) was used for the separation of glutathione (GSH) and PC variants, during which two mobile phases $0.02 \%$ TFA- $\mathrm{H}_{2} \mathrm{O}$ (A) and $0.02 \%$ TFA-ACN (B) were used for programmed elution (0-25 min, B 2\%-25\%) at a flow rate of $0.15 \mathrm{~mL} \mathrm{~min}^{-1}$. On-line GSH and PCs derivatization and determination were performed using 1.8 mmol L ${ }^{-1}$ DTNB containing $15 \mathrm{mmol} \mathrm{L}^{-1}$ EDTA and 0.3 mol L ${ }^{-1} \mathrm{~K}_{2} \mathrm{HPO}_{4}$ buffer ( $\mathrm{pH} 7.88$ ) delivered to join in the HPLC effluent via a T-joint using an isocratic pump (LC-20AD, Shimadzu, Kyoto, Japan) at a flow rate of 0.05 $\mathrm{mL} \min ^{-1}$ and determination at $410 \mathrm{~nm}$. Electrospray ion trap mass spectrometry (ESI-IT-MS) (ESQUIRELC, Bruker 
Daltonics, Germany) was used for identifying PCs and the operational parameters were: nebulizer, 75 psi; dry gas, 8 $\mathrm{L} \min ^{-1}$; dry temperature, $300^{\circ} \mathrm{C}$; capillary voltage, $-3500 \mathrm{~V}$; end plate offset, $-500 \mathrm{~V}$. A DRC II inductively coupled plasma mass spectrometer (ICP-MS) (PerkinElmer, Sciex, Canada) was used for online simultaneous determination of ${ }^{202} \mathrm{Hg}$ and ${ }^{32} \mathrm{~S}^{16} \mathrm{O}$ in the effluent from the size-exclusion chromatography (SEC) (Superdex peptide 10/300 GL 10 I.D. $\times 300 \mathrm{~mm}$ in length, $13 \mu \mathrm{m}$ particle size, optimum separation range 100-7000 Da, GE Healthcare, USA). The ICP-MS operational parameters were: Ar nebulizer gas, $0.18 \mathrm{~L} \mathrm{~min}^{-1}$; Ar auxiliary gas, $1.0 \mathrm{~L} \mathrm{~min}^{-1}$; Ar plasma gas, $15 \mathrm{~L} \mathrm{~min}^{-1}$; RF power, $1200 \mathrm{~W}$; dwell time, $100 \mathrm{~ms}$; lens voltage, $7.2 \mathrm{~V}$; DRC O $\mathrm{D}_{2}$ inlet, $0.6 \mathrm{~mL} \mathrm{~min}^{-1}$. The SEC fractions containing $\mathrm{Hg}$ and $\mathrm{S}$ were also collected and analyzed using a matrix-assisted laser desorption ionization time-offlight mass spectrometer (MALDI-TOF-MS) (microflex, Bruker Daltonics, Germany). The instrument was equipped with an $\mathrm{N}_{2}$ laser emitting at $337 \mathrm{~nm}$; spectra were acquired in the reflector positive-ion mode; ion source $1(19.01 \mathrm{kV})$, ion source $2(15.96 \mathrm{kV})$, laser power $(20 \mu \mathrm{J})$, reflector $(19.99 \mathrm{kV})$ and pulsed ion extraction (140 ns) were adopted, and 2, 5-dihydroxybenzoic acid was used as the matrix. After derivatization using $\mathrm{NaBPh}_{4}, \mathrm{MeHg}$ identification was performed using a Shimadzu GC-MS QP2010 (Shimadzu, Japan) equipped with an electron impact ion source and an Agilent DB-XLB $(15 \mathrm{~m} \times 0.25 \mathrm{~mm} \times 0.25 \mu \mathrm{m})$ capillary column. Injection temperature was set at $250^{\circ} \mathrm{C}$, and column oven temperature was programmed as $120^{\circ} \mathrm{C}$ increased to $230^{\circ} \mathrm{C}$ at $10^{\circ} \mathrm{C} \mathrm{min}{ }^{-1}$ held for $5 \mathrm{~min}$, then increased to $280^{\circ} \mathrm{C}$ at $25^{\circ} \mathrm{C} \mathrm{min}^{-1}$ held for $2 \mathrm{~min}$; column flow was 0.8 $\mathrm{mL} \min ^{-1} \mathrm{He}$; and the $\mathrm{m} / \mathrm{z}$ scan range was from 60 to 310 .

\subsection{P. tricornutum culture and exposure}

P. tricornutum was obtained from the Center for the Collection of Marine Bacteria and Phytoplankton in the State Key Laboratory of Marine Environmental Science, Xiamen University, China. Stock cultures of $P$. tricornutum were grown in axenic conditions at $(20 \pm 1)^{\circ} \mathrm{C}$ under illumination with fluorescent daylight (100 $\mu \mathrm{mol}$ (photon) $\mathrm{m}^{-2} \mathrm{~s}^{-1}$ with a 14:10 h light: dark cycle). The culture medium was natural seawater, which was passed through a Millipore filter of pore size $0.45 \mu \mathrm{m}$ and sterilized at $120^{\circ} \mathrm{C}$ for $20 \mathrm{~min}$ containing the modified $\mathrm{f} / 2$ enrichment solution [18]. The cultures were manually shaken daily in order to increase the growth rate of $P$. tricornutum and collect larger amounts of biomass. Stock cultures $(100 \mathrm{~mL})$ were used to inoculate $1 \mathrm{~L}$ of the culture medium. After 4 days culture and before the addition of $\mathrm{HgCl}_{2}$ and/or the corresponding ligands of HA, Trp, Cys, Met, NTA and EDTA, respectively, the acidity of the culture solutions was adjusted and buffered using $0.01 \mathrm{~mol} \mathrm{~L}^{-1} \mathrm{MOPS}$ at $\mathrm{pH}$ 7.5. The exposed P. tricornutum suspension $(4 \mathrm{~mL})$ was collected daily and its optical density was measured using a spectrophotometer at $680 \mathrm{~nm}$ wavelength (which is related to the absorption of chlorophyll $a$ ). The number of $P$. tricornutum in the $4 \mathrm{~mL}$ suspension was obtained based on the linear correlation between the optical density and the cell numbers counted using microscopy.

\subsection{Hg toxicity towards $P$. tricornutum and total, surface-bound and intracellular $\mathrm{Hg}$ accumulated by $P$. tricornutum}

The cell density of $P$. tricornutum was adopted as an indicator of $\mathrm{Hg}$ toxicity. After washing with natural seawater (filtered and sterilized prior to use) for three times and centrifuging at $4000 \times g$, the obtained $P$. tricornutum cells from $25 \mathrm{~mL}$ culture solution were subjected to digestion with concentrated $\mathrm{HNO}_{3}$ overnight, then diluted with ultrapure water for CVG-AFS to obtain the total amount of $\mathrm{Hg}$ accumulated. Surface-bound and intracellular $\mathrm{Hg}$ amounts were obtained as follows: the $P$. tricornutum cells were collected from $25 \mathrm{~mL}$ culture solution via centrifugation at $4000 \times g$ for $10 \mathrm{~min}$, and the $\mathrm{Hg}$ remaining in the supernatant was determined using CVG-AFS. The P. tricornutum cell pellets obtained were washed three times using the natural seawater to remove any substrate and then resuspended for $10 \mathrm{~min}$ in $10 \mathrm{~mL} 0.01 \mathrm{~mol} \mathrm{~L}^{-1}$ DTE solution to remove the $\mathrm{Hg}$ adsorbed on the cell walls [19], the $\mathrm{Hg}$ in the supernatant after centrifugation at $5000 \times g$ for $15 \mathrm{~min}$ and digestion with $\mathrm{HNO}_{3}$ was finally determined using CVG-AFS to obtain the amount of surface-bound $\mathrm{Hg}$. The $P$. tricornutum cells obtained after washing by DTE were subjected to $\mathrm{HNO}_{3}$ digestion and then determined using CVG-AFS to obtain the amount of intracellular $\mathrm{Hg}$. The amounts of total, surface-bound and intracellular $\mathrm{Hg}$ in the control group were determined to be $(0.25 \pm 0.2),(0.14 \pm 0.1)$ and $(0.11 \pm 0.1)$ $\mu \mathrm{g} \mathrm{g}^{-1}$, and were used to correct the experimental results.

\section{$1.5 \quad \mathrm{Hg} \mathrm{EC}_{50}$ towards $P$. tricornutum}

To investigate the toxicity of $\mathrm{HgCl}_{2}$ to $P$. tricornutum, the alga was cultured under exposure to $\mathrm{HgCl}_{2}$ at different concentrations $(20,40,80,100,120,140,160,180$ and 200

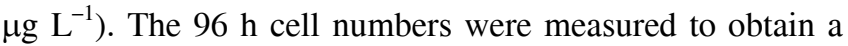
concentration-inhibition curve of the growth inhibition rate, which was calculated from the cell density determined against $\mathrm{HgCl}_{2}$ concentration. The $96 \mathrm{~h} \mathrm{EC}_{50}$ value for $P$. tricornutum was estimated to be $145 \mu \mathrm{g} \mathrm{L} \mathrm{L}^{-1} \mathrm{HgCl}_{2}$.

\subsection{Hg-containing fractions and phytochelatins (PCs) inside $P$. tricornutum}

An intracellular $\mathrm{NH}_{4} \mathrm{HCO}_{3}$-extract $\left(\mathrm{N}_{2}\right.$ saturated $50 \mathrm{mmol}$ $\mathrm{L}^{-1} \mathrm{NH}_{4} \mathrm{HCO}_{3}$ under ice-cold, $\mathrm{pH}$ 7.8) was obtained after ultrasonication for $2 \mathrm{~min}$ and centrifugation at $20000 \times \mathrm{g}$ for $15 \mathrm{~min}$. The Hg-containing fractions were analyzed using 
SEC/ICP-MS, in which $50 \mathrm{mmol} \mathrm{L} \mathrm{L}^{-1} \mathrm{NH}_{4} \mathrm{HCO}_{3}$ solution $(\mathrm{pH} 7.8)$ was used as a mobile phase at a flow rate of 0.75 $\mathrm{mL} \mathrm{min}^{-1}$. In addition, the fractions containing $\mathrm{Hg}$ and $\mathrm{S}$ were collected; after lyophilization, and were analyzed using MALDI-TOF-MS.

$P$. tricornutum cells exposed to different concentrations of $\mathrm{HgCl}_{2}$ were collected, resuspended in ice-cold $1 \mathrm{~mol} \mathrm{~L}^{-1}$ $\mathrm{NaOH}-0.5 \%$ (w/w) $\mathrm{NaBH}_{4}$ for ultrasonic extraction of their PCs in an ice bath [20]. The homogenates were centrifuged at $20000 \times g$ for $15 \mathrm{~min}$ at $4^{\circ} \mathrm{C}$, and then a $500 \mu \mathrm{L}$ aliquot of the supernatant was subjected to reaction with $50 \mu \mathrm{L}$ TBP for $10 \mathrm{~min}$ to further reduce the disulfide-linkage of the PCs. An appropriate amount of $6 \mathrm{~mol} \mathrm{~L}^{-1} \mathrm{HCl}$ was then added to adjust the $\mathrm{pH}$ to 1 , and finally the homogenate was centrifuged again at $20000 \times g$ at $4{ }^{\circ} \mathrm{C}$. The supernatant obtained was used for the analysis of PCs using RP-HPLC with postcolumn DTNB derivatization. The assignments of the respective peaks were performed by directly infusing the HPLC effluents into ESI-IT-MS without postcolumn DTNB derivatization.

\subsection{Characterization of MeHg converted by $P$. tricor- nutum under $\mathrm{HgCl}_{2}$ exposure}

All the culture solutions were sterilized at $120^{\circ} \mathrm{C}$ for $20 \mathrm{~min}$, and stock cultures of $P$. tricornutum were grown in axenic conditions. Inoculation and other operation were performed in a sterile operating room. Cells were collected from 400 $\mathrm{mL} P$. tricornutum suspensions under $\mathrm{HgCl}_{2}$ exposure (20, 80 and $120 \mu \mathrm{g} \mathrm{L}^{-1}$, respectively) via centrifugation at $4000 \times g$. The obtained cell pellets and corresponding culture solutions were subjected to the following treatments: the cell pellets were resuspended in $10 \mathrm{~mL} 0.01 \mathrm{~mol} \mathrm{~L}^{-1}$ DTE for $10 \mathrm{~min}$ to wash off any surface-adsorbed $\mathrm{Hg}$, then the cells were collected via centrifugation at $5000 \mathrm{~g}$; after being resuspended in $2 \mathrm{~mL} \mathrm{KOH} / \mathrm{CH}_{3} \mathrm{OH}(25 \%$, w/v) solution [21], the cells were ultrasonicated then the homogenized suspension was extracted three times using $3 \mathrm{~mL} \mathrm{CH}_{2} \mathrm{Cl}_{2}$ on a SKY-200B rocker (SUKUN, Shanghai, China) at 250 $\mathrm{r} / \mathrm{min}$ for $1 \mathrm{~h}$ each time. After the $\mathrm{CH}_{2} \mathrm{Cl}_{2}$ phases obtained were combined and concentrated under a $\mathrm{N}_{2}$-blow, they were subjected to HPLC/CVG-AFS. While the culture solutions obtained were acidified using $20 \mathrm{~mL}$ concentrated $\mathrm{HCl}$ then extracted using $30 \mathrm{~mL} \mathrm{CH}_{2} \mathrm{Cl}_{2} \mathrm{~mL}$ and shaking for $1 \mathrm{~h}$. The obtained $\mathrm{CH}_{2} \mathrm{Cl}_{2}$ phase of the three extracts were combined and concentrated followed the same procedures as in the case of the intracellular extracts. Moreover, parts of all the above samples were derivatized using $\mathrm{NaBPh}_{4}$ after the addition of $0.1 \mathrm{~mL} 0.1 \%$ sulfuric acid, and then the derivatives were extracted using $2 \mathrm{~mL}$ hexane for GC-MS measurements. The results obtained from the control group using identical treatments were determined to be $(0.08 \pm 0.06)$ $\mu \mathrm{g} \mathrm{g}{ }^{-1}$ for P. tricornutum and $(0.07 \pm 0.04) \mathrm{ng} \mathrm{L}^{-1}$ for culture solution, and were used to correct all the results under $\mathrm{HgCl}_{2}$ exposure.

\section{Results and discussion}

\subsection{Growth status of $P$. tricornutum and distribution of accumulated $\mathrm{Hg}$}

The growth of $P$. tricornutum under exposure to various $\mathrm{Hg}$ species was evaluated in terms of cell density, which was determined using microscopic counting and visible spectrometry at $680 \mathrm{~nm}$. The relationship of the cell density and exposure time under different concentrations of $\mathrm{HgCl}_{2}$ is shown in Figure 1(a), indicating that the growth of P. tricornutum was inhibited when $\mathrm{HgCl}_{2}$ was added to the culture medium. After $6 \mathrm{~d}$ of exposure, the density of $P$. tricornutum decreased by $3.6 \%, 7.6 \%, 14.5 \%, 27.6 \%$ and $34.3 \%$ under the stress of $20,40,80,100$ and $120 \mu \mathrm{g} \mathrm{L}^{-1}$ $\mathrm{HgCl}_{2}$, respectively, when compared with that of the control, suggesting that the toxicity of $\mathrm{HgCl}_{2}$ becomes greater with increase in $\mathrm{HgCl}_{2}$ concentration. It should be noted that the growth rates of $P$. tricornutum under exposure to 100 and/or $120 \mu \mathrm{g} \mathrm{L}^{-1} \mathrm{HgCl}_{2}$ was remarkably decreased just after one day exposure, and then tended to a gently ascending plateau, implying that the $P$. tricornutum might have started possible self-detoxifying mechanisms. The $96 \mathrm{~h} \mathrm{EC}_{50}$ value for $P$. tricornutum was estimated to be $145 \mu \mathrm{g} \mathrm{L} \mathrm{L}^{-1} \mathrm{HgCl}_{2}$ based on the concentration-inhibition curve of the cell density against $\mathrm{HgCl}_{2}$ concentration from 20 to $200 \mu \mathrm{g} \mathrm{L}^{-1}$. The total $\mathrm{Hg}$ accumulated by $P$. tricornutum increased from 196 to 2229 $\mu \mathrm{g} \mathrm{g}^{-1}$ dry weight (DW) after $6 \mathrm{~d}$ of exposure alongside the increase in $\mathrm{HgCl}_{2}$ concentration from 20 to $120 \mu \mathrm{g} \mathrm{L}^{-1}$ (Figure 1(b)). The amounts of $\mathrm{Hg}$ adsorbed on the surface of the cell wall (surface-bound $\mathrm{Hg}$ ) increased from 108 to $1847 \mu \mathrm{g} \mathrm{g}^{-1}$ DW while those inside the cell (intracellular $\mathrm{Hg}$ ) from 88 to $382 \mu \mathrm{g} \mathrm{g}^{-1}$ DW (Figure 1(c)). Bioaccumulation factors of $\mathrm{Hg}$ by $P$. tricornutum were $7.27 \times 10^{4}$ (intracellular $\mathrm{Hg}$ ), $8.86 \times 10^{4}$ (surface-bound $\mathrm{Hg}$ ) and $1.61 \times 10^{5}$ (total $\mathrm{Hg}$ ) under the exposure of $20 \mu \mathrm{g} \mathrm{L}{ }^{-1} \mathrm{HgCl}_{2} ; 2.04 \times 10^{4}, 4.73$ $\times 10^{4}$ and $6.77 \times 10^{4}$ under $40 \mu \mathrm{g} \mathrm{L}^{-1} \mathrm{HgCl}_{2} ; 8.82 \times 10^{3}$, $3.87 \times 10^{4}$ and $4.75 \times 10^{4}$ under $80 \mu \mathrm{g} \mathrm{L}^{-1} \mathrm{HgCl}_{2} ; 7.66 \times 10^{3}$, $4.23 \times 10^{4}$ and $5.00 \times 10^{4}$ under $100 \mu \mathrm{g} \mathrm{L}^{-1} \mathrm{HgCl}_{2}$; and 7.44 $\times 10^{3}, 3.59 \times 10^{4}$ and $4.34 \times 10^{4}$ under $120 \mu \mathrm{g} \mathrm{L}^{-1} \mathrm{HgCl}_{2}$. The amounts of surface-bound $\mathrm{Hg}$ were about 1.2 to 4.8 times higher than those for intracellular $\mathrm{Hg}$, suggesting that the cell wall played a more important role in accumulating and/or scavenging $\mathrm{Hg}$. The interactions of cell walls with $\mathrm{Hg}$ are also suggested by FT-IR studies (Figure 2) showing that the transmittance at $3437 \mathrm{~cm}^{-1}$ was shifted to $3433 \mathrm{~cm}^{-1}$ after adsorption. This change might result from the chemical interaction of $\mathrm{Hg}$ with $\mathrm{N}-\mathrm{H}$ and/or $\mathrm{O}-\mathrm{H}$ groups present on the cell wall. After $\mathrm{Hg}$ adsorption, the $\mathrm{C}=\mathrm{O}$ stretching vibration band shifted from 1647 to $1652 \mathrm{~cm}^{-1}$, indicating that the $N$-acetyl group I band of proteins was involved in the cell-adsorption process of $\mathrm{Hg}$. A significant shift was observed from 1068 to $1006 \mathrm{~cm}^{-1}$ after the cell-adsorption of $\mathrm{Hg}$, suggesting that the chemical interactions take place between $\mathrm{Hg}$ and the $\mathrm{Si}-\mathrm{O}$ or $\mathrm{C}-\mathrm{O}$ of the saccharide on the 

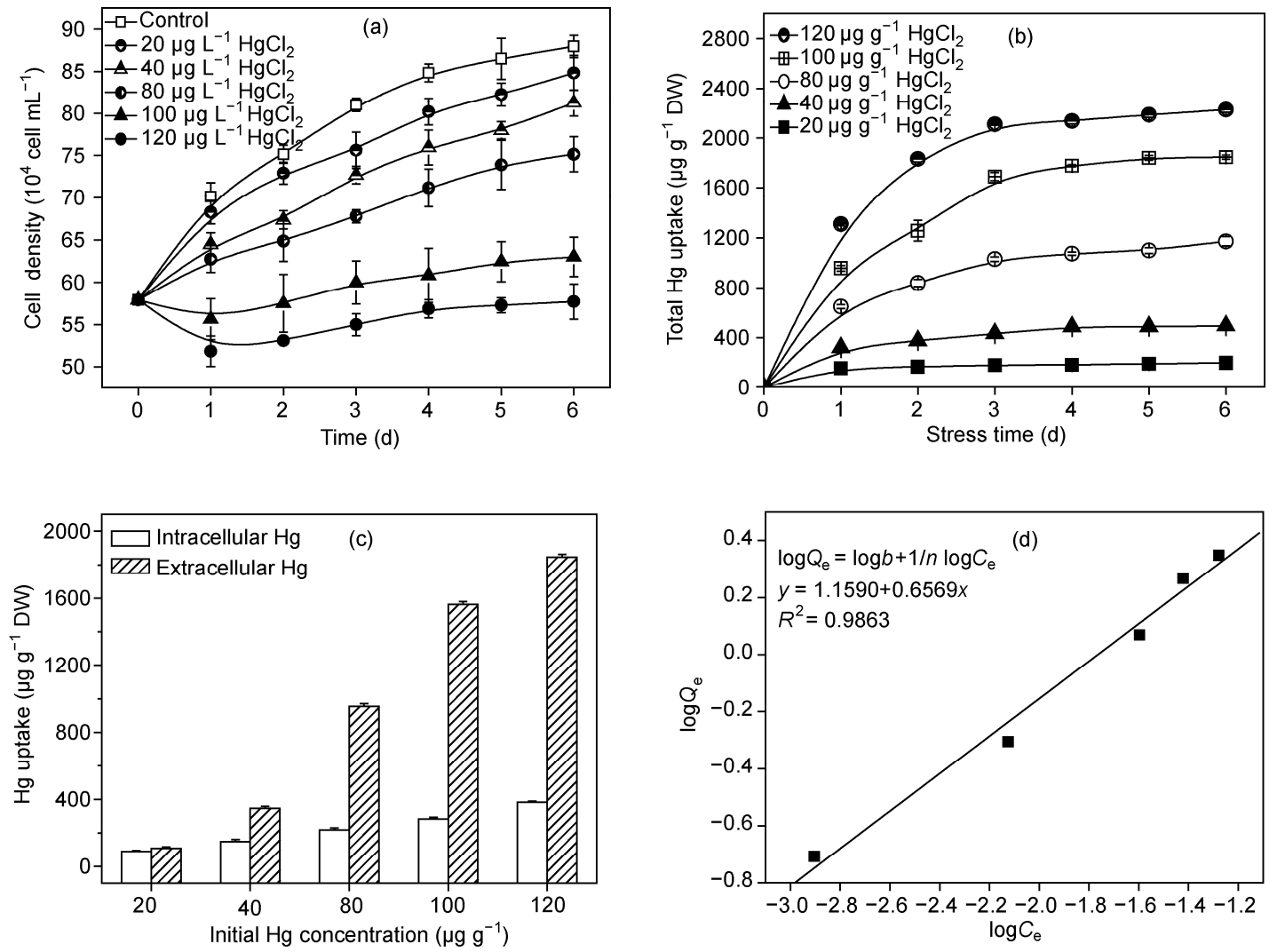

Figure 1 (a) Growth curves of $P$. tricornutum cells exposed to $\mathrm{HgCl}_{2}$. (b) Total $\mathrm{Hg}$ accumulated by $P$. tricornutum cells exposed to $\mathrm{HgCl}$ as a function of exposure time. (c) The intracellular and surface-bound distribution of $\mathrm{Hg}$ on P. tricornutum. (d) Freundlich isotherm of Hg adsorbed by P. tricornutum where $\log C_{e}$ is the logarithm of the equilibrium concentration of the $\mathrm{Hg}\left(\mathrm{mg} \mathrm{L}^{-1}\right)$, and $\log Q_{\mathrm{e}}$ is the logarithm of the amount adsorbed (mg g $\mathrm{g}^{-1}$ ). Error bars represent the standard deviations of triplicate culture experiments.

cell wall. These results revealed the interactions between $\mathrm{Hg}$ and different functional groups such as amine, carboxyl, hydroxyl and silanol on the cell wall of P. tricornutum. Langmuir and Freundlich adsorption isotherm models were applied to understand the accumulation processes of $\mathrm{Hg}$ onto $P$. tricornutum, and the results obtained indicated that the accumulation of $\mathrm{Hg}$ by $P$. tricornutum was in accordance with the typical heterogeneous Freundlich adsorption process according to $\log Q_{\mathrm{e}}=\log b+(1 / n) \log C_{\mathrm{e}}$, where $Q_{\mathrm{e}}$ is the amount adsorbed $\left(\mathrm{mg} \mathrm{g}^{-1}\right), C_{\mathrm{e}}$ is the equilibrium concentration of the $\mathrm{Hg}\left(\mathrm{mg} \mathrm{L}^{-1}\right)$, and $b$ and $n$ are the indicators of the adsorption capacity and adsorption intensity. Here, $b=14.42$ and $n=1.52$ (Figure $1(\mathrm{~d})$ ), and so the adsorption capacity and intensity are similar but somewhat weaker than typical $\mathrm{Hg}$ biosorbents such as Spirulina platensis $(b=$ 81.43, $n=3.765)$ and Aphanothece flocculosa $(b=141.61$, $n=5.672$ ) [22]. This result further confirmed a heterogeneous process of $\mathrm{Hg}$ accumulation by $P$. tricornutum, in which $\mathrm{Hg}$ interacted with the functional groups mentioned above and then entered the cell, resulting in both surface-bound and intracellular $\mathrm{Hg}$ distribution.

It is well known that ligands may change the chemical forms of heavy metals in the environment. Here Cys, Met, Trp and HA were chose as natural occurring ligands and

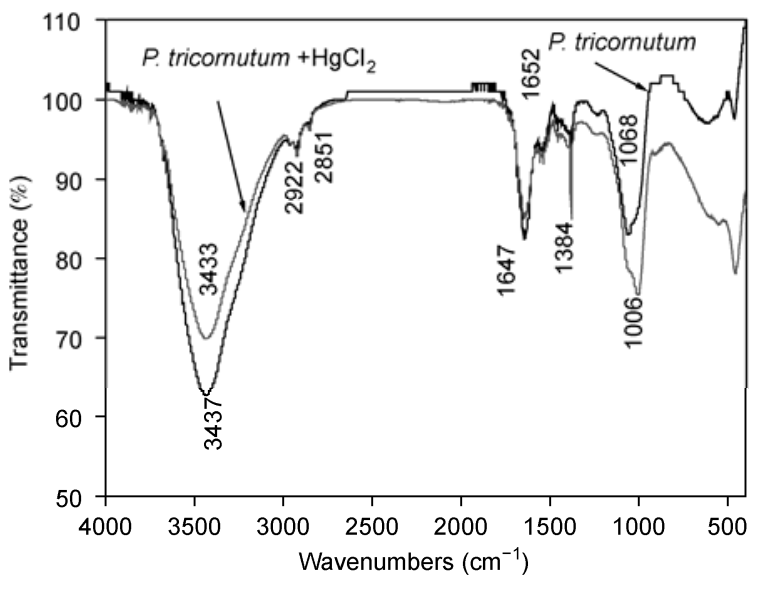

Figure 2 FT-IR spectra of $P$. tricornutum cell wall before and after celladsorption of $\mathrm{Hg}$. The cells were stressed by $120 \mu \mathrm{g} \mathrm{L}^{-1} \mathrm{HgCl}_{2}$.

NTA and EDTA as anthropogenic ligands to mimic those in the seawater, and added respectively into the $\mathrm{Hg}$-containing seawater culture solutions. $\mathrm{HgCl}_{2}$ forms different chemical species accordingly with the ligands added, and these species formed, in turn, determine the toxicity of $\mathrm{Hg}$ and the sorption behavior as well as their intracellular transformation $[23,24]$. The results obtained indicated that the 
growth status of $P$. tricornutum was inhibited remarkably in general in the culture solutions containing $\mathrm{Hg}$ and the ligands when compared with the control (Figure 3(a)). But compared with $\mathrm{HgCl}_{2}\left(100 \mu \mathrm{g} \mathrm{L}^{-1}\right)$ alone in the culture solution, there was a $6.1 \%$ increase in the cell density when HA was added and $4.2 \%$ in the case of EDTA. These phenomena might be ascribed to the strong coordination abilities of HA (the stability constant $\log K>30$ for $\mathrm{Hg}$-HA) [25] and EDTA $(\log K=21.7)$ [26] to $\mathrm{Hg}$, which greatly decreased the free $\mathrm{Hg}^{2+}$ concentration in the culture solution to $2.9 \times 10^{-9} \mu \mathrm{g} \mathrm{L}^{-1}$ under the same mole concentration of HA (molecular weight was taken as $3373 \mathrm{D}, 0.5 \mu \mathrm{mol} \mathrm{L}{ }^{-1}$ ) or EDTA $\left(0.5 \mu \mathrm{mol} \mathrm{L} \mathrm{L}^{-1}\right)$. The corresponding total, surfacebound and intracellular $\mathrm{Hg}$ accumulated decreased $13.3 \%$, $12.1 \%$ and $18.3 \%$ for $\mathrm{HA}$, and $8.5 \%, 6.8 \%$ and $17.6 \%$ for EDTA. Inhibition of $P$. tricornutum growth was observed when Met $\left(0.5 \mu \mathrm{mol} \mathrm{L}{ }^{-1}\right)$, Trp $\left(0.5 \mu \mathrm{mol} \mathrm{L}{ }^{-1}\right)$ or NTA $(0.5$ $\left.\mu \mathrm{mol} \mathrm{L} \mathrm{L}^{-1}\right)$ were added into the culture medium, and the cell densities decreased $19.0 \%, 7.9 \%$ and $4.7 \%$ when compared with that of $\mathrm{HgCl}_{2}\left(100 \mu \mathrm{g} \mathrm{L}^{-1}\right)$. However, the corresponding total, surface-bound and intracellular $\mathrm{Hg}$ increased by $31.1 \%, 30.0 \%$ and $36.1 \%$ for Met, $12.2 \%, 11.4 \%$ and $16.6 \%$ for Trp, and $8.3 \%, 7.8 \%$ and $10.9 \%$ for NTA (Figure 3(b)-(d)). Met and Trp improved the accumulation of $\mathrm{Hg}$ and chaperoned more $\mathrm{Hg}$ into the cell than did NTA. The $\mathrm{Hg}$ was complexed by all three, and easily taken into the cells, where it became more toxic than in the inorganic form
$\mathrm{HgCl}_{2}$ [27]. It is worth noting, however, that the addition of Cys $\left(0.5 \mu \mathrm{mol} \mathrm{L}{ }^{-1}\right)$ alleviated the toxicity of $\mathrm{Hg}$ and was favorable to the growth of $P$. tricornutum; the cell density increased $8.7 \%$ when compared with that of $\mathrm{HgCl}_{2}(100 \mu \mathrm{g}$ $\mathrm{L}^{-1}$ ) although there were $18.5 \%, 17.8 \%$ and $22.6 \%$ increases for the total, surface-bound and intracellular $\mathrm{Hg}$ accumulated, implying that Cys might play a special role in detoxifying the toxicity of $\mathrm{Hg}$ towards $P$. tricornutum.

\subsection{Transformation of $\mathbf{H g}$ inside $\boldsymbol{P}$. tricornutum}

In order to understand the transformation of $\mathrm{Hg}$ species inside the $P$. tricornutum cell and the possible corresponding detoxifying mechanisms, we analyzed the intracellular extract of $P$. tricornutum (with $\mathrm{NH}_{4} \mathrm{HCO}_{3}, \mathrm{pH}$ 7.8) using SEC/ UV/ICP-MS. The results obtained are shown in Figure 4(a). $\mathrm{Hg}$ and $\mathrm{S}$ were simultaneously detected in two main fractions (retention time from 8.0 to 10.5 and 20.3 to $22.6 \mathrm{~min}$ on the SEC). According to the calibration curve on the SEC using the standard compounds of known molecular weight under the same chromatographic conditions, we could estimate the $\mathrm{Hg}$ associated with high molecular weight (HMW) biomolecules (MW $>20 \mathrm{kD}$ ) in the first fraction (accounting for $68 \%$ of the intracellular $\mathrm{Hg}$ ) and low molecular weight biomolecules ( $\mathrm{MW}<1500 \mathrm{D}$ ) in the second fraction (24\%). It should be noted that the first fraction had a strong absorption at $280 \mathrm{~nm}$ but the second fraction had almost no
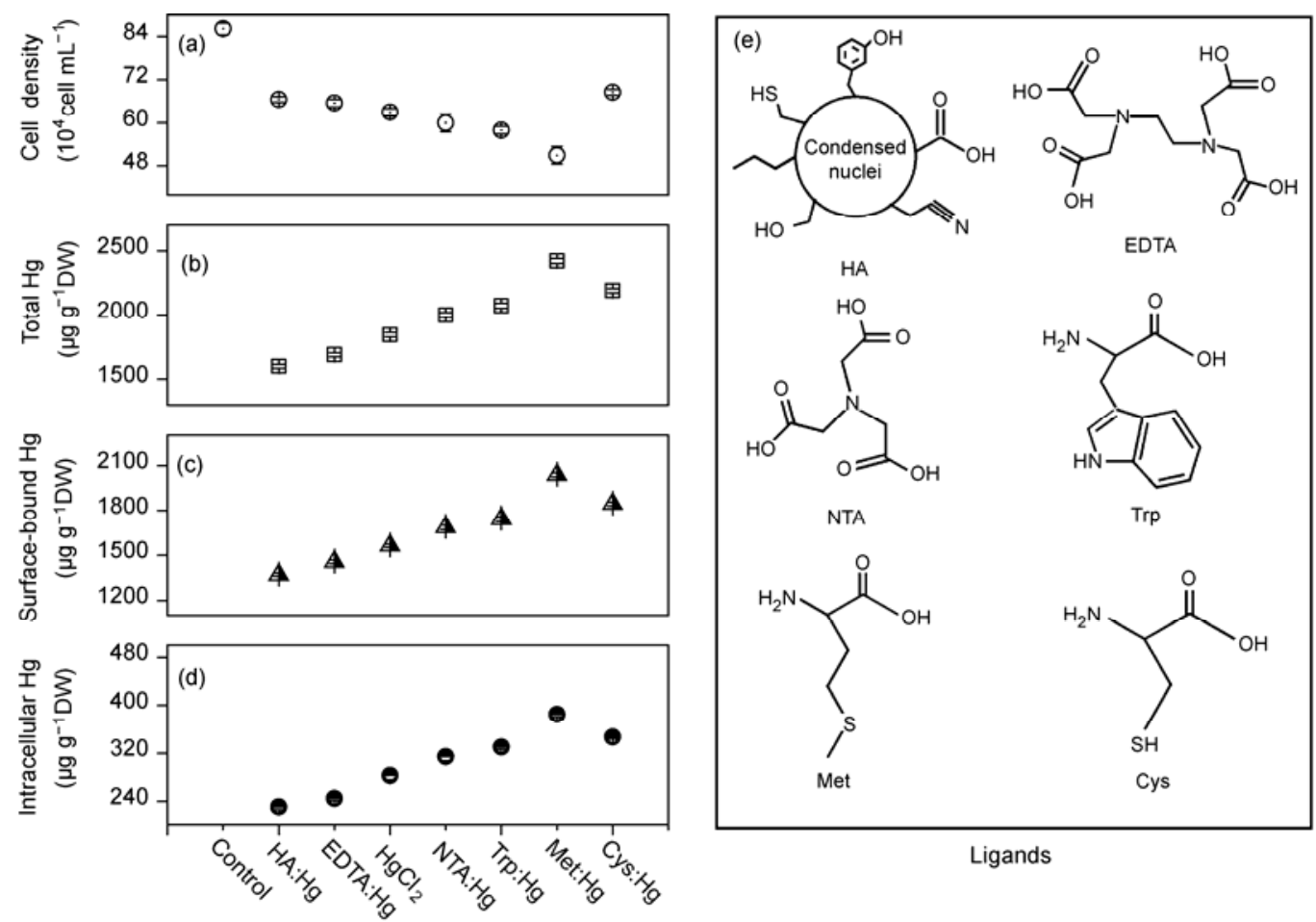

Figure 3 The cell density of P. tricornutum under exposure to $100 \mu \mathrm{g} \mathrm{L}^{-1} \mathrm{HgCl}_{2}$ alone and together with different ligands after $6 \mathrm{~d}$ (a). The total (b), surface-bound (c) and intracellular (d) $\mathrm{Hg}$ accumulated by P. tricornutum. The molar concentration ratio of $\mathrm{Hg}$ and the ligand was $1: 1$. The structure of the ligands (e). Error bars represent the standard deviations of triplicate cultures. 

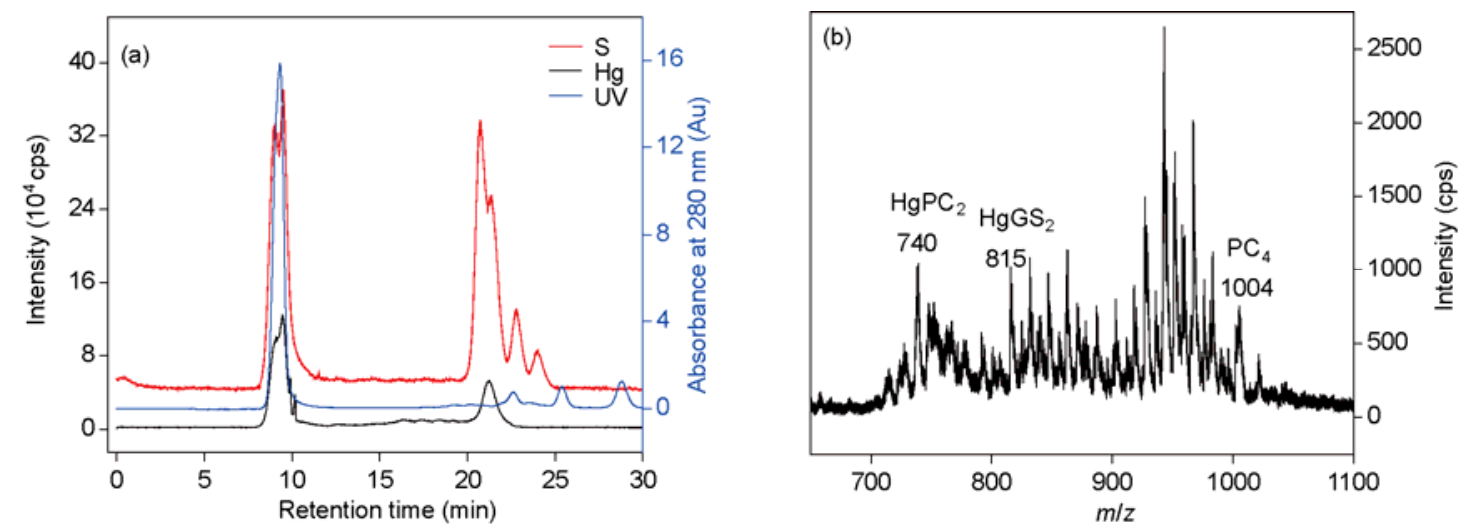

Figure $4 \mathrm{SEC} / \mathrm{UV} / \mathrm{ICP}-\mathrm{MS}$ showing the different $\mathrm{Hg}$ fractions in an $\mathrm{NH}_{4} \mathrm{HCO}_{3}$-soluble intracellular extract of $P$. tricornutum exposed to $120 \mu \mathrm{g} \mathrm{L}^{-1} \mathrm{HgCl}_{2}$ for $6 \mathrm{~d}$ (a). The red line represents the $\mathrm{S}$ signals, the black line the $\mathrm{Hg}$ signals and the blue line the UV absorbance at $280 \mathrm{~nm}$, MALDI-TOF-MS spectrum (in positive ion mode) of the second fraction (b).

absorption at $280 \mathrm{~nm}$. In this regard, we can speculate that $\mathrm{Hg}$ interacted with large proteins in the first fraction while in the second fraction with small peptides not containing phenylalanine, Trp and tyrosine such as GSH and PCs. This was confirmed by the fact that $\mathrm{HgGS}_{2}$ and $\mathrm{HgPC}_{2}$, as well as $\mathrm{PC}_{4}$, were observed when the fraction was determined using MALDI-TOF-MS (Figure 4(b)). Previous studies also showed that some water plants (Hydrilla verticillata and Vallisneria spiralis L. [17]), a microalga (Thalassiosira weissflogii [28]) as well as some terrestrial plants (Brassica napus [29] and Brassica chinensis L. [30]) can produce PCs under the exposure to $\mathrm{Hg}$.

In order to further investigate the intracellular metabolic behavior or defense mechanisms of $P$. tricornutum when exposed to $\mathrm{Hg}$, the second intracellular fraction of $P$. tricornutum was acidified to $\mathrm{pH} 1$ then infused into ESI-ITMS. GSH and $\mathrm{PC}_{2}$ to $\mathrm{PC}_{5}$ were detected $\left([\mathrm{GSH}+\mathrm{H}]^{+}, \mathrm{m} / z\right.$ 308; $\left[\mathrm{PC}_{2}+\mathrm{H}\right]^{+}, \mathrm{m} / z$ 540; $\left[\mathrm{PC}_{3}+\mathrm{H}\right]^{+}, \mathrm{m} / \mathrm{z} 772 ;\left[\mathrm{PC}_{4}+\mathrm{H}\right]^{+}, \mathrm{m} / \mathrm{z}$ $1004 ;\left[\mathrm{PC}_{5}+\mathrm{H}\right]^{+}, m / z$ 1236), confirming that $\mathrm{Hg}$ indeed induced the production of PCs inside $P$. tricornutum cells. The amounts of PCs induced were determined using DTNBderivatization spectrophotometry at $410 \mathrm{~nm}$ (Figure 5 and Table 1). The results obtained under the exposure of different amounts of $\mathrm{Hg}$ indicated that not only the amount but also the type of PCs increased along with the increase in $\mathrm{Hg}$ concentration in the culture solution. When $\mathrm{Hg}$ concentration was $120 \mu \mathrm{g} \mathrm{L}^{-1}, 65 \pm 13 \mathrm{nmol} \mathrm{g}^{-1} \mathrm{PC}_{2}, 36 \pm 11 \mathrm{nmol} \mathrm{g}^{-1}$ $\mathrm{PC}_{3}, 37 \pm 10 \mathrm{nmol} \mathrm{g}^{-1} \mathrm{PC}_{4}$ and $16 \pm 8 \mathrm{nmol} \mathrm{g}^{-1} \mathrm{PC}_{5}$ were induced. These results suggested that $P$. tricornutum was able to synthesize PCs to defend against the toxicity of $\mathrm{Hg}$, in which Cys is an important precursor [30]. This helps us to explain the phenomenon whereby Cys in the culture solution can enhance the uptake of not only the total $\mathrm{Hg}$ but also the surface-bound and intracellular $\mathrm{Hg}$ while alleviating the toxicity of $\mathrm{Hg}$ when compared with the other ligands added. We thus speculated that the intrinsic defence mechanism of $P$. tricornutum was triggered to start synthesizing PCs when exposed to $\mathrm{Hg}$, which in turn alleviated cellular toxicities

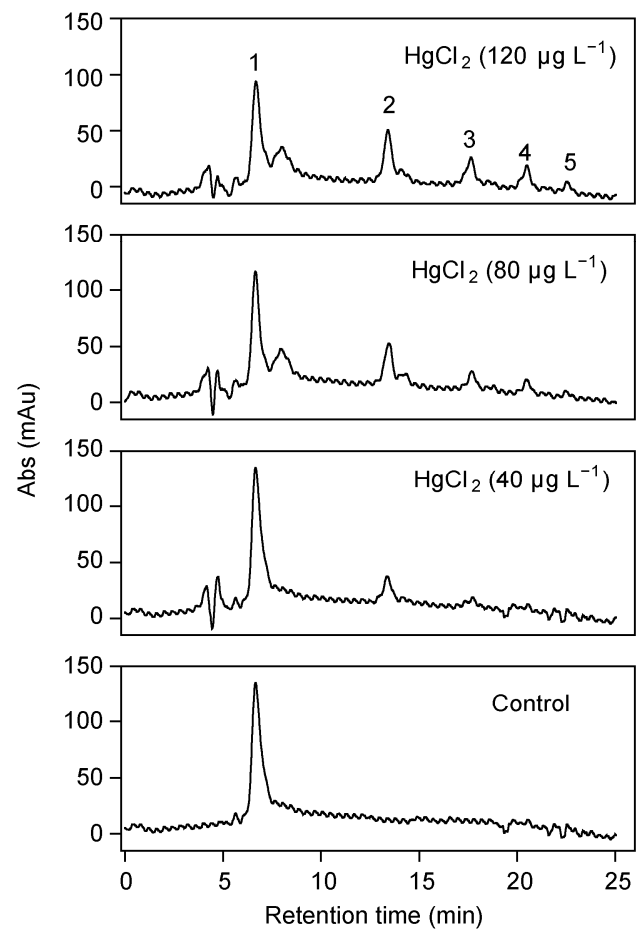

Figure 5 Chromatogram of PCs produced by $P$. tricornutum under the exposure of different concentrations of $\mathrm{HgCl}_{2}$. The identified peaks using ESI-IT- MS are GSH (1), $\mathrm{PC}_{2}(2), \mathrm{PC}_{3}(3), \mathrm{PC}_{4}(4)$, and $\mathrm{PC}_{5}(5)$.

through their superior mutual interactions.

More surprisingly, $\mathrm{MeHg}$ was observed both inside the cells and in the culture solution when $P$. tricornutum was exposed by $\mathrm{HgCl}_{2}$ (Figure 6). As we know, $\mathrm{MeHg}$ is a more toxic form of $\mathrm{Hg}$ and the major risk to the health of humans via consumption of contaminated fish and rice in some $\mathrm{Hg}$ contaminated areas [6,31]. It is well documented that $\mathrm{MeHg}$ can be transformed from inorganic $\mathrm{Hg}$ in natural waters via biological ways (for example, periphyton [32], plankton produced iodomethane [33], macroalgae [34,35] and especially anoxic bacteria such as sulfate-reducing bacteria [36] in deep and littoral sediments are found to produce methylated 
Table 1 Amount of GSH and PCs induced in P. tricornutum after exposure to different concentrations of $\mathrm{Hg}$ a)

\begin{tabular}{ccccccc}
\hline \multirow{2}{*}{ Exposure conditions } & \multicolumn{7}{c}{ GSH and PCs $\left(\mathrm{nmol} \mathrm{g}^{-1} \mathrm{DW}\right)$} & \multirow{2}{*}{$\Sigma \mathrm{PC}\left(\mu \mathrm{mol} \mathrm{g} \mathrm{g}^{-1} \mathrm{DW}\right)$} \\
\cline { 2 - 5 } & $\mathrm{GSH}$ & $\mathrm{PC}_{2}$ & $\mathrm{PC}_{3}$ & $\mathrm{PC}_{4}$ & $\mathrm{PC}_{5}$ & 0 \\
Control & $103 \pm 15$ & n.d. & n.d. & n.d. & n.d & $0.11 \pm 0.1$ \\
$\mathrm{Hg}^{\text {b) }}(40)$ & $109 \pm 13$ & $39 \pm 8.3$ & $12 \pm 6.8$ & n.d. & n.d. & $0.23 \pm 0.1$ \\
$\mathrm{Hg}^{\text {b) }}(80)$ & $97 \pm 11$ & $46 \pm 9.6$ & $19 \pm 6.5$ & $20 \pm 8.9$ & n.d & $0.47 \pm 0.2$ \\
$\mathrm{Hg}^{\text {b) }}(120)$ & $88 \pm 12$ & $65 \pm 13$ & $36 \pm 11$ & $37 \pm 10$ & $16 \pm 8$ & 0.2 \\
\hline
\end{tabular}

a) All values were expressed as mean $\pm \mathrm{SD}$ of three repetitions from triplicate cultivations; DW, dry weight; $\Sigma \mathrm{PC}$, molar concentrations of the sum of $\gamma$-Glu-Cys units of the detected PC variants. n.d., not detected. b) $\mu \mathrm{g} \mathrm{L^{-1 }}$.

mercury) and non-biological ways [37] (such as methyltin, methylcobalamin and humic matter in sediments). In order to verify the production of $\mathrm{MeHg}$ when P. tricornutum was exposed to $\mathrm{HgCl}_{2}$, we detected and identified $\mathrm{MeHg}$ in both the intracellular extract of $P$. tricornutum and the corresponding culture solution using HPLC-AFS and GC-MS. $\mathrm{MeHg}$ was detected in the $P$. tricornutum culture solutions using HPLC-AFS (Figure 6(b)) strictly following the $\mathrm{MeHg}$ extraction protocols [21], but no $\mathrm{MeHg}$ was detected in the control culture solutions containing no $P$. tricornutum. This was further confirmed by the GC-MS results which showed the $\mathrm{Hg}$ species of $\mathrm{MeHgPh}(\mathrm{m} / \mathrm{z}=294), \mathrm{HgPh}(279), \mathrm{MeHg}$ (217) and $\mathrm{Hg}$ (202) as well as $\mathrm{Ph}$ (77), when using $\mathrm{NaBPh}_{4}$ derivatization and electron impact as the ion source (Figure 6(c) and (d)). After one day of $\mathrm{HgCl}_{2}$ exposure (at 20, 80 and $120 \mu \mathrm{g} \mathrm{L}^{-1}$, respectively), the amounts of $\mathrm{MeHg}$ produced were found to be $2.1,6.2$ and $9.8 \mu \mathrm{g} \mathrm{g}^{-1} \mathrm{DW}$ inside $P$.
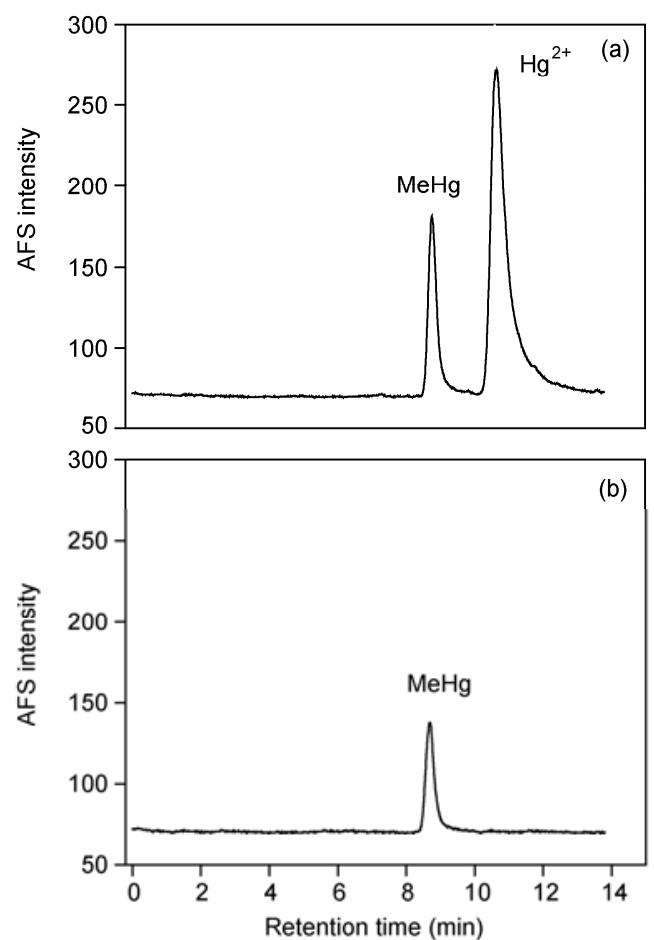

tricornutum; and 27, 42 and $63 \mathrm{ng} \mathrm{L}^{-1}$ in the culture solutions. Although the amount of $\mathrm{MeHg}$ to total $\mathrm{Hg}$ is much small, these results suggested that $P$. tricornutum could not only produce $\mathrm{MeHg}$ inside its cells but also release it into the culture solution. The relative lower $\mathrm{MeHg}$ concentration in the culture solution might be ascribed to the slow release rate of $\mathrm{MeHg}$ from P. tricornutum and the escape into the atmosphere from the culture solution due to its relatively higher vapor pressure at high ionic strengths (such as in the sea water used in this study) [38,39]. Although these observations were made, little is known at this moment concerning the methylating mechanism of $P$. tricornutum. More intensive research should be performed in the near future.

In conclusion, $P$. tricornutum can accumulate $\mathrm{Hg}$ and its bioaccumulation factor is at $10^{4}$ levels. After biouptake, $\mathrm{Hg}$ inside $P$. tricornutum undergoes species transformation through interactions with the induced HMW sulfur-containing
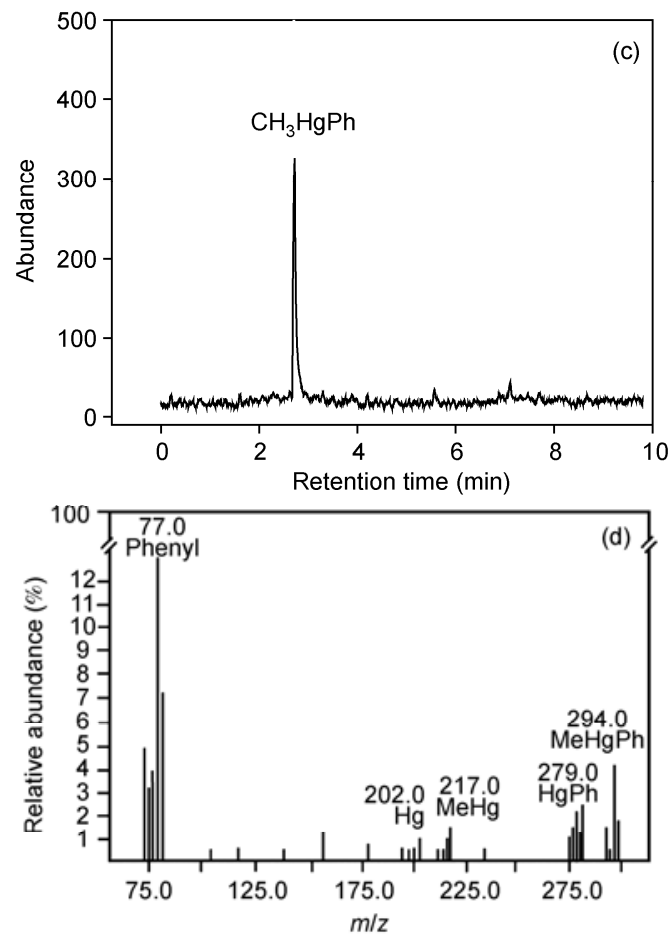

Figure 6 (a) The typical HPLC-AFS chromatogram of $\mathrm{MeHg}^{+}$and $\mathrm{Hg}^{2+}$ standards, $0.5 \mathrm{mg} \mathrm{L}{ }^{-1}$, sample injection $10 \mu \mathrm{L}$; (b) the typical HPLC-AFS chromatogram of the intracellular extract of $P$. tricornutum under the exposure of $120 \mu \mathrm{g} \mathrm{L}^{-1} \mathrm{HgCl}_{2}$; (c), (d) the GC-MS spectrum of the intracellular extract of $P$. tricornutum under the exposure of $120 \mu \mathrm{g} \mathrm{L} \mathrm{L}^{-1} \mathrm{HgCl}_{2}$ with $\mathrm{NaBPh}_{4}$ derivatization. 
proteins and PCs alleviating the toxicity of $\mathrm{Hg}$; although the mechanism needs further and intensive investigation, on the other hand, $P$. tricornutum has the ability to convert $\mathrm{HgCl}_{2}$ into $\mathrm{MeHg}$, and to release the $\mathrm{MeHg}$ out of the cells, thus behaving as another defense mechanism. Even though all these characteristics of $P$. tricornutum were observed under the exposure of extremely high $\mathrm{Hg}$ concentration hopefully understanding the possible mechanisms of acute $\mathrm{Hg}$ stress response at this moment, these knowledge learned was helpful to understand the self-cleaning ability of aquatic ecosystems and the biogeochemical cycling of $\mathrm{Hg}$ as well as the bioaccumulation and biomagnification of $\mathrm{Hg}$ along the food-chain. Clearly, further researches are expected to perform under the exposure of $\mathrm{Hg}$ at the nature levels to find the chronic exposure response of $P$. tricornutum, so that a more comprehensive and accurate understanding of the role of marine algae in the self-cleaning ability of the oceans and the biogeochemical cycling of $\mathrm{Hg}$ can be achieved.

This work was supported by the National Basic Research Program of China (2009CB421605) and the National Natural Science Foundation of China (21035006). Professor John Hodgkiss of The University of Hong Kong is thanked for assistance with the English in this paper.

1 Tobin J M, White C, Gadd G M. Metal accumulation by fungi: Applications in environmental biotechnology. J Ind Microbiol, 1994, 13: 126-130

2 Mendoza-Cózatl D G, Rodríguez-Zavala J S, Rodríguez-Enríquez S, et al. Phytochelatin-cadmium-sulfide high-molecular-mass complexes of Euglena gracilis. FEBS J, 2006, 273: 5703-5713

3 Pongratz R, Heumann K G. Production of methylated mercury, lead, and cadmium by marine bacteria as a significant natural source for atmospheric heavy metals in polar regions. Chemosphere, 1999, 39: 89-102

4 Jiang G B, Shi J B, Feng X B. Mercury pollution in China. Environ Sci Technol, 2006, 40: 3672-3678

5 Fitzgerald W F, Lamborg C H, Hammerschmidt C R. Marine biogeochemical cycling of mercury. Chem Rev, 2007, 107: 641-662

6 Clarkson T W. The three modern faces of mercury. Environ Health Perspect, 2002, 110: 11-23

7 Wang X Y, Li Y F, Li B, et al. Multielemental contents of foodstuffs from the Wanshan (China) mercury mining area and the potential health risks. Appl Geochem, 2011, 26: 182-187

8 Li P, Feng X B, Shang L H, et al. Mercury pollution from artisanal mercury mining in Tongren, Guizhou, China. Appl Geochem, 2008, 23: 2055-2064

9 Feng X B, Dai Q Q, Qiu G L, et al. Gold mining related mercury contamination in Tongguan, Shaanxi Province, PR China. Appl Geochem, 2006, 21: 1955-1968

10 Pickhardt P C, Fisher N S. Accumulation of inorganic and methylmercury by freshwater phytoplankton in two contrasting water bodies. Environ Sci Technol, 2007, 41: 125-131

11 Chen C Y, Dionne M, Mayes B M, et al. Mercury bioavailability and bioaccumulation in estuarine food webs in the gulf of maine. Environ Sci Technol, 2009, 43: 1804-1810

12 Bowler C, Allen A E, Badger J H, et al. The Phaeodactylum genome reveals the evolutionary history of diatom genomes. Nature, 2008, 456: 239-244

13 Morelli E, Marangi M L, Fantozzi L. A phytochelatin-based bioassay in marine diatoms useful for the assessment of bioavailability of heavy metals released by polluted sediments. Environ Int, 2009, 35: 532-538

14 Horvatić J, Peršić V. The effect of $\mathrm{Ni}^{2+}, \mathrm{Co}^{2+}, \mathrm{Zn}^{2+}, \mathrm{Cd}^{2+}$ and $\mathrm{Hg}^{2+}$ on the growth rate of marine diatom Phaeodactylum tricornutum Bohlin: microplate growth inhibition test. Bull Environ Contam Toxicol, 2007, 79: 494-498

15 Zheng C B, Li Y, He Y H, et al. Photo-induced chemical vapor generation with formic acid for ultrasensitive atomic fluorescence spectrometric determination of mercury: Potential application to mercury speciation in water. J Anal At Spectrom, 2005, 20: 746-750

16 Yin Y M, Liang J, Yang L M, et al. Vapor generation at a $\mathrm{UV} / \mathrm{TiO}_{2}$ photocatalysis reduction device for determination and speciation of mercury by AFS and HPLC-AFS. J Anal At Spectrom, 2007, 22: 330-334

17 Yin Y M, Qiu J H, Yang L M, et al. A new vapor generation system for mercury species based on the UV irradiation of mercaptoethanol used in the determination of total and methyl mercury in the environmental and biological samples by atomic fluorescence spectrometry. Anal Bioanal Chem, 2007, 388: 831-836

18 Guillard R R L. Culture of phytoplankton for feeding marine invertebrates. In: Smith W L, Chanley M H, eds. Culture of Marine Invertebrate Animals. New York: Plenum Press, 1975. 29-60

19 Kelly D, Budd K, Lefebvre D D. Mercury analysis of acid- and alkaline-reduced biological samples: Identification of meta-cinnabar as the major biotransformed compound in algae. Appl Environ Microbiol, 2006, 72: 361-367

20 Gupta M, Tripathi R D, Rai U N, et al. Role of glutathione and phytochelatin in Hydrilla verticillata (I.f.) royle and Vallisneria spiralis L. under mercury stress. Chemosphere, 1998, 37: 785-800

21 Liang L, Horvat M, Cernichiari E, et al. Simple solvent extraction technique for elimination of matrix interferences in the determination of methylmercury in environmental and biological samples by ethylation-gas chromatography-cold vapor atomic fluorescence spectrometry. Talanta, 1996, 43: 1883-1888

22 Cain A, Vannela R, Woo L K. Cyanobacteria as a biosorbent for mercuric ion. Bioresour Technol, 2008, 99: 6578-6586

23 Lamelas C, Slaveykova V I. Comparison of $\mathrm{Cd}(\mathrm{II}), \mathrm{Cu}(\mathrm{II})$, and $\mathrm{Pb}$ (II) biouptake by green algae in the presence of humic acid. Environ Sci Technol, 2007, 41: 4172-4178

24 Zhong H, Wang W X. Controls of dissolved organic matter and chloride on mercury uptake by a marine diatom. Environ Sci Technol, 2009, 43: 8998-9003

25 Khwaja A R, Bloom P R, Brezonik P L. Binding constants of divalent mercury $\left(\mathrm{Hg}^{2+}\right)$ in soil humic acids and soil organic matter. Environ Sci Technol, 2006, 40: 844-849

26 Shetty P, Shetty A N, Gadag R V. Complexometric determination of mercury(II) using 2-mercaptopropionylglycine as a selective masking reagent. Mikrochim Acta, 2001, 137: 71-73

27 Hongve D, Skogheim O K, Hindar A, et al. Effects of heavy metals in combination with NTA, humic acid, and suspended sediment on natural phytoplankton photosynthesis. Bull Environm Contam Toxicol, 1980, 25: 594-600

28 Morelli E, Ferrara R, Belline B, et al. Changes in the non-protein thiol pool and production of dissolved gaseous mercury in the marine diatom Thalassiosira weissflogii under mercury exposure. Sci Total Environ, 2009, 408: 286-293

29 Iglesia-Turiño S, Febrero A, Jauregui O, et al. Detection and quantification of unbound phytochelatin2 in plant extracts of Brassica napus grown with different levels of mercury. Plant Physiol, 2006, 142: 742-749

30 Chen L Q, Yang L M, Wang Q Q. In vivo phytochelatins and $\mathrm{Hg}$ phytochelatin complexes in Hg-stressed Brassica chinensis L. Metallomics, 2009, 1: 101-106

31 Zhang H, Feng X B, Larssen T, et al. In inland China, rice, rather than fish, is the major pathway for methylmercury exposure. Environ Health Perspect, 2010, 118: 1183-1188

32 Desrosiers M, Planas D, Mucci A. Mercury methylation in the epilithon of boreal shield aquatic ecosystems. Environ Sci Technol, 2006, 40: 1540-1546

33 Minganti V, Capelli R, Drava G, et al. Solubilization and methylation of $\mathrm{HgS}, \mathrm{PbS}$, and $\mathrm{SnS}$ by iodomethane, a model experiment for the aquatic environment. Chemosphere, 2007, 67: 1018-1024 
34 Pongratz R, Heumann K G. Production of methylated mercury and lead by polar macroalgae-A significant natural source for atmospheric heavy metals in clean room compartments. Chemosphere, 1998, 36: 1935-1946

35 Tsui M T K, Finlay J C, Balogh S J, et al. In situ production of methylmercury with a stream channel in northern California. Environ Sci Technol, 2010, 44: 6998-7004

36 Gilmour C C, Henry E A, Mitchell R. Sulfate stimulation of mercury methylation in freshwater sediments. Environ Sci Technol, 1992, 26:
2281-2287

37 Bloom N S, Lasorsa B K. Changes in mercury speciation and the release of methyl mercury as a result of marine sediment dredging activities. Sci Total Environ, 1999, 238: 379-385

38 Jonsson S, Skyllberg U, Björn E. Substantial emission of gaseous monomethylmercury from contaminated water-sediment microcosms. Environ Sci Technol, 2010, 44: 278-283

39 Olson K R. Loss of carbon-14 and mercury-203 labeled methylmercury from various solutions. Anal Chem, 1977, 49: 23-26

Open Access This article is distributed under the terms of the Creative Commons Attribution License which permits any use, distribution, and reproduction in any medium, provided the original author(s) and source are credited. 